\title{
A Comparison Between Late Preterm and Term Infants on Breastfeeding and Maternal Mental Health
}

\author{
Sheila W. McDonald • Karen M. Benzies • \\ Jenna E. Gallant $\cdot$ Deborah A. McNeil · \\ Siobhan M. Dolan · Suzanne C. Tough
}

Published online: 7 October 2012

(C) The Author(s) 2012. This article is published with open access at Springerlink.com

\begin{abstract}
The objective of this study was to compare breastfeeding, postpartum mental health, and health service utilization between a group of late preterm (LP) maternal infant pairs and term counterparts. Data was drawn from a prospective community-based cohort in Calgary, Alberta. Bivariate and multivariable analyses were performed. LP infants were more likely to have had a longer median length of stay after birth $(P<0.001)$ and a higher re-hospitalization rate at 4-months $(P<0.001)$ compared to term infants. Mothers of LP infants were more likely to report immediate breastfeeding difficulties $(P<0.001)$ and earlier cessation of breastfeeding at 4-months postpartum $(P=0.008)$. Multivariable analyses revealed that LP status was an independent risk factor for excessive symptoms of maternal anxiety $(\mathrm{OR}=2.07 ; 95 \% \mathrm{CI}=1.08,3.98)$, but
\end{abstract}

S. W. McDonald $(\bowtie) \cdot$ S. C. Tough

Department of Paediatrics, Faculty of Medicine,

University of Calgary, Calgary, AB, Canada

e-mail: sheilaw.mcdonald@albertahealthservices.ca

K. M. Benzies · J. E. Gallant

Faculty of Nursing, University of Calgary, Calgary,

$\mathrm{AB}$, Canada

D. A. McNeil

Department of Population and Public Health, Alberta Health

Services, Calgary, AB, Canada

S. M. Dolan

Department of Obstetrics and Gynecology and Women's Health, Albert Einstein College of Medicine/Montefiore Medical Center, Bronx, NY, USA

S. C. Tough

Department of Community Health Sciences, Faculty of

Medicine, University of Calgary, Calgary,

$\mathrm{AB}$, Canada not for depression, stress, or low parenting morale. LP infants and their families are a vulnerable population with unique developmental trajectories. Further longitudinal research is required.

Keywords Breastfeeding - Late preterm .

Maternal mental health · Postpartum

\section{Introduction}

It has been well established that being born preterm ( $<37$ weeks gestational age) is associated with adverse health and development outcomes for the infant that extend into the early childhood and beyond. These include neonatal morbidities, delays in motor, cognitive, and behavioral functioning during early childhood, and increased risk for chronic disease later in life [1-4]. Preterm births, however, comprise a heterogeneous group with accepted designations of risk comprising very early ( $<32$ weeks), early $\left(32^{0 / 7}-33^{6 / 7}\right.$ weeks), and late preterm births $\left(34^{0 / 7}\right.$ $36^{6 / 7}$ weeks). The term, 'late preterm' (LP) was introduced by the National Institute of Child Health and Human Development in 2005 to replace the previous descriptor, 'near term', to more accurately capture this high risk group as preterm, requiring individual treatment according to their specific needs [5]. In the United States, LP births account for approximately $70 \%$ of all preterm deliveries [6], with Canadian data reporting a similarly high proportion (74\%) [7]. Recent trends have shown an overall increase in the preterm birth rate; especially conspicuous in the United States, the preterm birthrate has increased by $36 \%$ in 25 years, with increases in LP births accounting for much of this rise [8]. Indeed, between 1990 and 2005, US statistics show that while the rate of births before 
34 weeks gestation has remained unchanged, the LP birthrate has increased during the same time period $[9,10]$. Although a slight decline in the LP birth rate in 2007 in the US has been reported [11], overall, LP births are both the fastest growing and largest subgroup of preterm births in North America [8].

Often comparable in birth weight and appearance to term infants, LP infants lag in development across a number of domains rendering them medically vulnerable $[12,13]$. LP newborns are frequently cared for in the general postpartum care units despite their higher risk of physiological issues such as feeding difficulties, weight loss, respiratory distress, hypoglycemia, hypothermia, hyperbilirubinemia, postural instability, immature oromotor development, and lethargy compared to term infants [13-18]. Many of these physiological dangers place LP infants at increased risk of morbidity and mortality compared to their term counterparts [19-21]. These LP infants often require additional observation time in the hospital, continued therapies, and are more likely to be re-admitted, or have a longer initial length of stay post delivery [21, 22], all of which translate into increased demands on the healthcare system, as well as to mothers, families, and caregivers.

While the extant literature in this area suggests that short-term medical risks are common for LP infants, more research is needed to examine long-term outcomes [23]. There are only a limited number of reports documenting later-life outcomes for LP infants, and more prospectively collected data is required to validate existing observations [24]. One recent prospective investigation, drawing from a longitudinal study of cognitive and behavioral outcomes associated with low birth weight, found that at 6 years of age, children that were born LP were more likely to have lower IQ and behavior problems compared to term counterparts even after controlling for maternal IQ and socioeconomic status [25]. These findings align with an earlier population-based study which found increased risk for adverse school-age outcomes for LP infants [26, 27]. Although null findings have also been reported [28], a recent systematic review on early childhood development of LP infants concluded that LP infants are at increased risk of poor developmental outcomes (e.g., neurodevelopmental disabilities, poor educational ability, early-intervention requirements) up to school age compared to term infants [23].

Potential mediators and moderators of threats to development are also understudied for children born LP; these outcomes include maternal and family health factors [2] and emotional responses. Some researchers have suggested that mothers of LP infants are at risk of persistent anxiety and depression [29]. This is of particular concern given the influence of maternal mental health after birth on infant and child development [30-34]. Reports on maternal symptomatology associated with early preterm births have noted increased rates of depression, anxiety, and stress in both the short and long-term [35-39]. Of the few studies that have examined maternal mental health with respect to the LP infant, similar findings have been reported [29, 40], yet given differences in study design, timing of assessment, control for confounding variables, and source of sample population, more research is needed to inform the evidence base that drives clinical practice and policy recommendations. One small study that examined maternal mental health on day 3-4 postpartum found increased levels of anxiety, depression, and stress among mothers of LP infants compared to term infants, which, in turn, led to earlier cessation of breastfeeding [41]. A recent study examined emotional distress among mothers of LP infants up to 1 month postpartum and found increased levels of anxiety, depression, post-traumatic stress, and worry compared to mothers of term infants [40], yet limitations noted by the authors such as small sample size, lack of baseline emotional distress, and high-risk referral source, indicate that further research is required.

In summary, LP births constitute a growing public health concern yet knowledge gaps remain concerning long-term outcomes for infants and their families. In particular, postpartum mental health constitutes a significant area of investment for further research to identify effective prevention and intervention strategies to support these families. This study evaluated the independent influence of LP birth on maternal symptoms of anxiety, depression, and stress, while controlling for maternal demographic factors and mental health history. Furthermore, this study examined parenting morale among LP mothers, a measure of psychological well-being that taps into a mother's internal coping resources. Finally, this study compared immediate postnatal experiences including breastfeeding experiences and health care utilization between a group of LP maternal-infant pairs and their term counterparts.

\section{Materials and Methods}

The All Our Babies (AOB; $n=1,654$ ) study is a community-based prospective pregnancy cohort study in Calgary, Alberta that began in 2008. The overall aims were to examine maternal well-being during the perinatal period and infant outcomes such as preterm birth, and to identify the current barriers and facilitators to accessing prenatal care. Participation in the study involved the completion of three mailed questionnaires ( $<24$ weeks, 34-36 weeks, 4-months postpartum) and consent for linkage to medical records. The response rate across the three time points was 
over $80 \%$, with pregnancy loss or lost to follow-up constituting the most common reasons for attrition.

The questionnaires, which included standardized scales and investigator derived questions, inquired about sociodemographics, lifestyle, heath care utilization, stress, depression, anxiety, birth outcomes, parenting morale, and breastfeeding, among other variables. Data were cleaned to align with pre-existing data coding and cleaning guidelines $[42,43]$. For the present study, data were analyzed using the SPSS statistical software program (Version 19.0).

For the purposes of the present study, we restricted the sample $(\mathrm{n}=1,227)$ to women giving birth to a singleton infant and excluded those with a self-reported gestational age of 37 weeks in order to limit the potential for misclassification of term status. Two groups of women were compared: a group of mothers who self-reported a gestational age at delivery between 34 and 36 weeks (latepreterm; $\mathrm{n}=77)$ and those who delivered at 38 weeks or more $(\mathrm{n}=1,150)$. For the present analysis, the following validated instruments were used: the Edinburgh Postnatal Depression Scale (EPDS) [44], the Cohen Perceived Stress Scale (PSS) [45], the Spielberger State Anxiety Index (SSAI) [46], and the Parenting Morale Index [47], to measure maternal symptoms of depression, stress, anxiety, and parenting morale, respectively. Example items for each standardized scale and other variables of interest for the present study are shown in section Appendix.

LP and term groups were compared on maternal characteristics as well as prenatal and immediate postpartum experiences, using Chi Square test/Fisher's exact test for categorical variables and Independent Samples $t$ test/MannWhitney $U$ for continuous variables. Distributional assumptions were checked prior to analysis to ensure test appropriateness (parametric vs. non-parametric). Multivariable logistic regression models were performed to examine the extent to which birth status was a significant independent predictor of excessive symptoms of anxiety, depression, stress, and parenting morale at 4-months postpartum, controlling for known risk factors and confounding variables. Demographics, prepregnancy maternal characteristics, and select pregnancy variables that were significant at the bivariate level $(P<0.1)$ were considered for inclusion in the multivariable analyses as confounding variables. Excluded predictors or variables not significant at the bivariate level were added to the final models, one at a time, to ensure that important confounding variables were not missed. Factors that were considered to be intermediate variables on the causal pathway between birth status and postpartum mental health outcomes (e.g., breastfeeding experiences, health care utilization) were not included in multivariable models as confounding variables as their inclusion could lead to bias of the association between birth status and mental health outcomes (i.e., 'overadjustment').
Blocks of variables were manually entered in a hierarchal fashion: demographic variables were entered first, followed by prepregnancy characteristics, prenatal mental health variables, and, finally, birth status. Finally, goodness-of-fit statistics and regression diagnostics were performed [48].

This study was approved by the Conjoint Health Research Ethics Board of the University of Calgary. Participants provided informed consent at the time of recruitment and were provided copies for their records.

\section{Results}

Comparison of birth status indicated that mothers of LP infants were significantly more likely to be non-Caucasian (37.3 vs. $22.2 \% ; P=0.003$ ), to report lower household income levels (27.4 vs. $16.9 \% ; P=0.02$ ), and to have had a previous preterm birth (12.0 vs. $9.1 \% ; P=0.01)$ (Table 1$)$. There were no significant differences between the two groups in terms of the other demographic and prepregnancy maternal characteristics examined. Table 2 shows comparisons between the two groups on pregnancy variables, delivery and health care utilization variables, and breastfeeding outcomes. Significant differences between the two groups were found for all factors that were compared except for substance use during pregnancy and delivery method. As expected, LP singleton infants were significantly more likely than term singleton infants to be in the low birth weight category $(<2,500 \mathrm{~g})(29.9$ vs. $1.0 \% ; P<0.001)$, and to have experienced a longer median length of stay in the hospital after birth ( 4 vs. 1.5 days; $P<0.001)$. Additionally, mothers of LP infants were more likely to have reported excessive prenatal anxiety ( 40.0 vs. $27.0 \% ; P=0.015)$ and prenatal depression symptoms (19.5 vs. $10.0 \%$; $P=0.009$ ), and to have experienced breastfeeding difficulties. In terms of the latter, LP infants were less likely to have breastfed within $24 \mathrm{~h}$ after birth (78.7 vs. $97.5 \%$; $P<0.001)$ as well as before leaving the hospital (78.1 vs. $90.8 \% ; P<0.001)$, and to be breastfeeding at 4 months (69.3 vs. $81.7 \% ; P=0.008$ ). Mothers of LP infants were more likely to report being unsuccessful on their first attempt at breastfeeding (50.7 vs. $75.0 \% ; P<0.001$ ) and to have consulted with a lactation professional before leaving the hospital (73.0 vs. $39.6 \% ; P<0.001)$. Finally, LP infants were significantly more likely than term infants to be rehospitalized before 4 months $(14.5$ vs. $3.8 \% ; P<0.001)$.

We performed four separate multivariable logistic regression models for each maternal mental health outcome at 4 months postpartum. We categorized mothers as reporting either excessive symptoms or not, according to validated or accepted cut-offs as per the literature (40 and above for anxiety) [46] and 13 and above for depression [44]. For perceived stress symptoms and parenting morale 
Table 1 Comparison of demographic and maternal characteristics (prepregnancy) between the late-preterm and full-term groups lbw low birth weight

${ }^{\text {a }}$ Denominator varies due to missing values for some variables

\begin{tabular}{|c|c|c|c|c|}
\hline Characteristic & $\begin{array}{l}\text { Total sample } \\
(\mathrm{n}=1,227) \\
\mathrm{n}(\%)\end{array}$ & $\begin{array}{l}\text { LPs } \\
(\mathrm{n}=77) \\
\mathrm{n}(\%)^{\mathrm{a}}\end{array}$ & $\begin{array}{l}\text { Terms } \\
(\mathrm{n}=1,150) \\
\mathrm{n}(\%)^{\mathrm{a}}\end{array}$ & $P$ value \\
\hline \multicolumn{5}{|l|}{ Maternal age } \\
\hline$<25$ years & $75(6.3)$ & $8(11.0)$ & $67(6.0)$ & \multirow[t]{3}{*}{0.24} \\
\hline $25-34$ years & $871(73.3)$ & $51(69.9)$ & $820(73.5)$ & \\
\hline $35+$ years & $243(20.4)$ & $14(19.2)$ & $229(20.5)$ & \\
\hline \multicolumn{5}{|l|}{ Education } \\
\hline High school or less & $123(10.1)$ & $7(9.3)$ & $116(10.1)$ & \multirow[t]{3}{*}{0.72} \\
\hline College, trade, university & $893(73.3)$ & $53(70.7)$ & $840(73.4)$ & \\
\hline Grad school & $203(16.7)$ & $15(20.0)$ & $188(16.4)$ & \\
\hline \multicolumn{5}{|l|}{ Household income } \\
\hline$<60,000$ & $207(17.5)$ & $20(27.4)$ & $187(16.9)$ & \multirow[t]{2}{*}{0.02} \\
\hline $60,000+$ & $974(82.5)$ & $53(72.6)$ & $921(83.1)$ & \\
\hline \multicolumn{5}{|l|}{ Marital status } \\
\hline Married/common-law & $1,156(94.9)$ & $73(97.3)$ & $1,083(94.8)$ & \multirow[t]{2}{*}{0.58} \\
\hline Other & $62(5.1)$ & $2(2.7)$ & $60(5.2)$ & \\
\hline \multicolumn{5}{|l|}{ Ethnic origin } \\
\hline White/Caucasian & 937 (76.9) & $47(62.7)$ & $890(77.8)$ & \multirow[t]{2}{*}{0.003} \\
\hline Other & $282(23.1)$ & $28(37.3)$ & $254(22.2)$ & \\
\hline \multicolumn{5}{|l|}{ Born in Canada } \\
\hline Yes & $942(77.2)$ & $53(70.7)$ & 889 (77.6) & \multirow[t]{2}{*}{0.16} \\
\hline No & $278(22.8)$ & $22(29.3)$ & $256(22.4)$ & \\
\hline \multicolumn{5}{|l|}{ History of depression } \\
\hline No & $841(68.9)$ & $56(74.7)$ & $785(68.7)$ & \multirow[t]{2}{*}{0.27} \\
\hline Yes & $379(31.1)$ & $19(25.3)$ & $360(31.4)$ & \\
\hline \multicolumn{5}{|c|}{ History of other mental health problems } \\
\hline No & $1,128(91.9)$ & $69(92.0)$ & $1,059(92.7)$ & \multirow[t]{2}{*}{0.84} \\
\hline Yes & $90(7.4)$ & $6(8.0)$ & $84(7.3)$ & \\
\hline \multicolumn{5}{|l|}{ History of abuse } \\
\hline No & $851(71.7)$ & $47(67.1)$ & $804(72.0)$ & \multirow[t]{2}{*}{0.38} \\
\hline Yes & $336(28.3)$ & $23(32.9)$ & $313(28.0)$ & \\
\hline \multicolumn{5}{|l|}{ Parity } \\
\hline 0 & $626(51.6)$ & $43(57.3)$ & $583(51.2)$ & \multirow[t]{2}{*}{0.30} \\
\hline $1+$ & $588(48.4)$ & $32(42.7)$ & $556(48.8)$ & \\
\hline \multicolumn{5}{|l|}{ Previous preterm birth } \\
\hline No & $1,155(94.7)$ & $66(88.0)$ & $1,089(95.2)$ & \multirow[t]{2}{*}{0.01} \\
\hline Yes & $64(15.3)$ & $9(12.0)$ & $55(9.1)$ & \\
\hline \multicolumn{5}{|l|}{ Previous lbw birth } \\
\hline No & $1,183(97.0)$ & $29(85.3)$ & $578(94.9)$ & \multirow[t]{2}{*}{0.07} \\
\hline Yes & $36(3.0)$ & $5(14.7)$ & $31(5.1)$ & \\
\hline \multicolumn{5}{|c|}{ Used active method to get pregnant } \\
\hline No & $1,151(94.4)$ & $74(98.7)$ & $1,077(94.1)$ & \multirow[t]{2}{*}{0.12} \\
\hline Yes & $68(5.6)$ & $1(1.3)$ & $67(5.9)$ & \\
\hline
\end{tabular}

at 4-months postpartum, we considered scoring above the 80th percentile (stress) or below the 20th percentile (parenting morale) of the distribution as manifestation of excessive stress and low parenting morale, respectively. Each multivariable model controlled for confounding variables, a number which are also established risk factors for poor postpartum mental health (e.g., history of depression, prenatal depression and prenatal anxiety) [49-51]. Final models are shown in Table 3; each model presents the odds ratios and $95 \%$ confidence intervals for term status as well as those covariates that remained significant at $P<0.05$. Excluded predictors were added, one 
Table 2 Comparison of pregnancy, delivery, and breastfeeding experiences between the late-preterm and full-term groups a Denominator varies due to missing values for some variables

\begin{tabular}{lccc}
\hline Characteristic & $\begin{array}{l}\text { LPs } \\
(\mathrm{n}=77) \\
\mathrm{n}(\%) / \text { median }(\mathrm{IQR})^{\mathrm{a}}\end{array}$ & $\begin{array}{l}\text { Terms } \\
(\mathrm{n}=1,150) \\
\mathrm{n}(\%) / \text { median }(\mathrm{IQR})^{\mathrm{a}}\end{array}$ \\
\hline $\begin{array}{l}\text { Pregnancy } \\
\text { Smoked during pregnancy }\end{array}$ & $8(11.0)$ & $98(8.7)$ & 0.50 \\
Consumed alcohol during pregnancy & $27(37.0)$ & $454(40.0)$ & 0.61 \\
Prenatal depression & $15(19.5)$ & $115(10.0)$ & 0.009 \\
Prenatal anxiety & $30(40.0)$ & $309(27.0)$ & 0.015 \\
Delivery and health care utilization & & & \\
C-section delivery & $19(24.7)$ & $243(21.2)$ & 0.47 \\
Birth weight $<2,500 \mathrm{~g}$ & $23(29.9)$ & $11(1.0)$ & $<0.001$ \\
Length of infant hospital stay (days) & $4.00(8.24)$ & $1.50(1.00)$ & $<0.001$ \\
Infant rehospitalization rate between & $11(14.5)$ & $42(3.8)$ & $<0.001$ \\
$\quad$ discharge and 4-months & & & \\
Breastfeeding & & $1,096(97.5)$ & $<0.001$ \\
Breastfeeding within 24 h after delivery & $59(78.7)$ & $841(75.0)$ & $<0.001$ \\
Successful breastfeeding on first attempt & $38(50.7)$ & $957(90.8)$ & $<0.001$ \\
Breastfeeding before leaving hospital & $57(78.1)$ & $434(39.6)$ & $<0.001$ \\
Saw a lactation consultant before leaving hospital & $54(73.0)$ & $919(81.7)$ & 0.008 \\
Still breastfeeding at 4-months postpartum & $52(69.3)$ &
\end{tabular}

Table 3 Final multivariable logistic regression models examining the independent contribution of birth status to parenting morale, maternal anxiety, depression, and stress symptomatology at 4-months postpartum

\begin{tabular}{|c|c|c|c|c|}
\hline Independent variable & $\begin{array}{l}\text { Anxiety } \\
\text { OR }(95 \% \mathrm{CI})\end{array}$ & $\begin{array}{l}\text { Depression } \\
\text { OR }(95 \% \mathrm{CI})\end{array}$ & $\begin{array}{l}\text { Stress } \\
\text { OR }(95 \% \mathrm{CI})\end{array}$ & $\begin{array}{l}\text { Parenting morale } \\
\text { OR }(95 \% \mathrm{CI})\end{array}$ \\
\hline Household income $(<\$ 60,000)$ & $1.55(1.00,2.42)$ & & $1.60(1.06,2.42)$ & \\
\hline Nulliparous & & & & $0.58(0.42,0.80)$ \\
\hline History of depression & $2.90(1.99,4.24)$ & $2.79(1.55,5.03)$ & $2.24(1.57,3.20)$ & $2.36(1.69,3.30)$ \\
\hline Prenatal anxiety & $5.16(3.44,7.74)$ & $3.95(2.01,7.78)$ & $3.88(2.66,5.66)$ & $3.54(2.49,5.03)$ \\
\hline Prenatal depression & $2.64(1.64,4.27)$ & $3.60(1.92,6.75)$ & $3.13(1.97,4.97)$ & $1.82(1.15,2.88)$ \\
\hline Ever experienced abuse & & & & $1.50(1.07,2.10)$ \\
\hline LP birth status & $2.07(1.08,3.98)$ & $0.73(0.24,2.23)$ & $1.34(0.69,2.61$ & $1.23(0.65,2.35)$ \\
\hline
\end{tabular}

Only those variable that remained significant at $P<0.05$ in the final multivariable model for each respective outcome are shown

Significance value for bolded $\mathrm{OR}$ is $P=0.029$

at a time, back into the final models to ensure that important confounding variables were not missed in the presence of other variables in the model. The final multivariable logistic regression analysis for anxiety symptoms at 4-months postpartum showed that mothers of LP infants were significantly more likely than mothers of term infants to report excessive anxiety $(\mathrm{OR}=2.07,95 \%$ $\mathrm{CI}=1.08,3.98)$, even after controlling for prenatal anxiety and depression, a history of depression, and household income (Table 3). LP status was not an independent risk factor in multivariable logistic regression models for depression, stress, or parenting morale at 4-months postpartum (Table 3).

\section{Comment}

Using data from a community-based prospective pregnancy cohort in Calgary, Alberta, we compared maternal characteristics, postnatal experiences, and symptoms of maternal anxiety, depression, stress, and parenting morale at 4-months postpartum between a group of mothers of LP infants $(n=77)$ and a group of mothers of term infants ( $n=1,150)$. The demographic profile of the AOB sample, in general, is representative of the urban pregnant and parenting population in Canada [52]. Controlling for baseline measures of distress, LP birth was associated with excessive anxiety symptoms at 4-months postpartum but 
not with depressive symptoms, stress, or with parenting morale. In addition, immediate postnatal healthcare utilization and breastfeeding outcomes were significantly different between the two groups.

The results corroborate previous studies that suggested that LP infants and their mothers are at risk of a number of poor outcomes both immediately after delivery and the months following birth. A recent review article reported increased hospitalization rates and delayed hospital discharge due to 'poor feeding' as compared to term infants or non-breastfeeding LP infants [53]. In our study we found similar results in terms of increased hospitalization rates and longer hospital stay after birth for LP infants compared to term births, findings consistent with previous reports for LP infants $[21,22,54]$. Our study did not allow for examination of specific reasons for delayed discharge or re-hospitalization, yet given their low breastfeeding initiation and success rates, poor feeding could be a contributing factor. There is some evidence to suggest earlier breastfeeding cessation rates for LPs compared to terms [53]. At 4 months postpartum, $69 \%$ of the LP group was still breastfeeding compared to $82 \%$ of the term group. Our lower rates of breastfeeding initiation and success as reported by mothers of LP infants are in line with reports that LP infants present challenges for breastfeeding success and duration due to inadequate milk transfer [55], physiological issues in the infant (e.g., cardio respiratory insufficiency, metabolic disturbances, uncoordinated suck-swallow-breathe mechanism), and NICU admission and consequent maternal-infant separation $[5,17,53,56]$. Given the longitudinal design of the AOB study, planned analyses include examining trajectories of feeding experiences across the early life course among LPs. Longitudinal data will help to further understand feeding trajectories, including exclusive breastfeeding rates according to the World Health Organization criteria (until 6 months of age and continuing for up to 2 years) [57].

Maternal anxiety and depression are often co-morbid conditions that occur in the postpartum [58-60]. Given the limited number of investigations on maternal mental health outcomes for mothers of LP infants, our community-based study is a welcome addition to supplement the current evidence base. The multivariable regression results of our study identified increased anxiety compared to other symptoms of poor mental health at 4-months post-delivery for mothers of LP infants, which is in contrast to a recent report of emotional responses of mothers of LP and term infants [40]. The authors of the latter found that mothers of LP infants had greater emotional distress on standardized measures for anxiety, depression, posttraumatic stress, and worry immediately following delivery and at one-month postpartum. As our follow-up time frame extended to 4-months postpartum, it is possible that initial levels of depressive and stress symptoms decrease over time. Yet this suggestion is in contrast to another recent study that reported elevated levels of both anxiety and depression 6-months after delivery among mothers of LP infants compared to term infants [29]. Indeed, the interplay between stress, anxiety, depression and parenting morale as well as the specificity for long-term anxiety beyond 4-months is an area for further investigation.

Our study, in contrast to the few previous studies examining postpartum mental health among mothers of LP infants, had the advantage of having collected information on, and therefore controlling for, a history of mental health difficulties and prenatal anxiety and depression in multivariable models for postpartum distress. It could be that significant associations between LP birth status and postpartum maternal depression and posttraumatic stress (for example) previously reported were due to residual confounding, as this type of information was unavailable in those studies. Additional strengths of the present study include its prospective design and population-based sample. By comparing a LP group to a term group with a lower bound for gestational age at 38 weeks versus the standard 37 weeks, we minimized misclassification of group status.

Given that all factors measured in the current study were based on maternal self-report, some error may have been introduced. We dichotomized mental health symptomatology as high or low; although previous studies have examined symptoms in continuous form, they also present categorical findings according to clinical cut-offs [40] and in the top quartile of the distribution [29]. The continuous scores showed evidence of skewness in our sample; for this reason and given the presence of established cut-offs in the literature for most of the scales, we used multivariable logistic regression to build the final models. Of note, a similar pattern of results was seen when linear regression modeling was done using transformed scores (results not shown). Regardless of how these scores are ultimately handled in analyses, all studies to date share the limitation imposed by the selfreport nature of maternal mental health symptoms and therefore conclusions on 'caseness' or diagnostic classification cannot be made. However, the prospective nature of data collection in our study minimizes the risk of recall bias of mental health at each data collection time point. An avenue for further research would be to examine the gradient of gestational age with maternal mental health symptomatology. The recent systematic review by McGowan et al. [23] on early childhood outcomes of LP infants concluded that LP infants fall between very preterm infants and term infants on a developmental outcome continuum, suggesting a 'scale' of prematurity, and an inverse, linear association between gestational age and risk of longer-term disability. Similarly, results from a recent population based cohort study [61] suggest a dose response effect of prematurity on health outcomes at 3 and 5 years of age. Such gradient effects warrant further investigation. 
Other possible reasons for discrepant results for postpartum mental health between our study and previous ones may concern the demographic and socioeconomic profile of study participants, as our study tended to attract women with higher than average education and household incomes. Given differences in the demographic profile of our participants, compared to the target populations of the relatively few studies on postpartum mental health among LP mothers $[29,40]$, which tend to be more diverse and/or characterized by low socioeconomic status, this data suggest that trajectories of maternal mental health among LP mothers of relatively affluent socioeconomic status may also differ.

In summary, results from our study suggest that LP infants are a vulnerable group, impacting both infant and maternal mental health, in particular, immediate breastfeeding challenges and excessive anxiety at 4-months postpartum. Whether this vulnerability extends across time remains largely unexplored. Given the unique challenges of LP birth [13], it is imperative that further research into the precursors, correlates, and outcomes associated with a LP birth continue in order to best support their specific maternal and infant needs.
Acknowledgments We are extremely grateful to all the families who took part in this study and the whole All Our Babies team. We are extremely grateful to the investigators, co-ordinators, research assistants, graduate and undergraduate students, volunteers, clerical staff and managers. Alberta Innovates Health Solutions provided funding for this cohort and additional funding from the Alberta Centre for Child, Family, and Community Research assisted with the analysis of data presented in this manuscript. Preterm Birth and Healthy Outcomes (PreHOT) Alberta Innovates Health Solutions Interdisciplinary Team Grant \#200700595.

\section{Conflict of interest None.}

Open Access This article is distributed under the terms of the Creative Commons Attribution License which permits any use, distribution, and reproduction in any medium, provided the original author(s) and the source are credited.

Table 4 Select variables assessed in the AOB study used in the present study

Candidate variable (data collection Source/phrasing time point $)^{\mathrm{a}}$

Standardized Scales

Prenatal and postnatal depressive symptoms (t1-t3):

Prenatal and postnatal stress symptoms (t1-t3):

Prenatal and postnatal anxiety symptoms (t1-t3):

\section{symptoms (t1- 13$):$}

al anxiety

Edinburgh Postnatal Depression Scale

Perceived Stress Scale

Spielberger State Anxiety Inventory
Scoring and/or coding information

\section{Appendix}

See Table 4.
10 item questionnaire. Each item rated on a 4-point Likert scale from 0 to 3 . After reverse scoring for some items, a total score is derived (range 0-30). Higher scores reflect increased depression. We used a standard cut-off as per the literature (13 and above) to identify high depressive symptoms. Participants are instructed to respond to each item with respect to the past 7 days. Example items include: "In the past 7 days, I have felt sad or miserable"; "In the past 7 days, I have been so unhappy that I have been crying"

10 item questionnaire. Each item rated on a 5-point Likert scale from 0 to 4 . After reverse scoring for some items, a total score is derived (range 0-40). Higher scores reflect increased stress. A cut-off at the 80th percentile of the sample distribution was used to classify women as manifesting high stress symptoms. Participants are instructed to respond to each item with respect to the past month. Example items include: "Felt unable to cope with all the things you had to do"; "Felt that difficulties were piling up so high that you couldn't overcome them"

20 item questionnaire. Each item rated on a 4-point Likert scale from 1 to 4 . After reverse scoring for some items, a total score is derived (range 20-80). Higher scores reflect increased anxiety. We used an established cut-off of 40 or more to classify women as experiencing high anxiety symptoms. Participants are instructed to respond to each item as of right now (in this moment). Example items include: "I feel anxious"; "I feel worried"; "I feel nervous" 
Table 4 continued

\begin{tabular}{lll}
\hline Candidate variable (data collection & Source/phrasing & Scoring and/or coding information
\end{tabular}
time point $)^{\mathrm{a}}$

Parenting morale symptoms (t3): $\quad$ Parenting Morale Index

Select single-item questions

Parity (t1):

History of depression (t1):

Ever experienced abuse ( $\mathrm{t} 2)$ :

Term/birth status (t3):

Length of infant hospital stay (days; $\mathrm{t} 3$ ):

Infant rehospitalization rate between discharge and 4-months (t3):

Breastfeeding within $24 \mathrm{~h}$ after delivery ( $\mathrm{t} 3)$ :

Successful breastfeeding on first attempt ( $\mathrm{t} 3$ ):

Breastfeeding before leaving the hospital (t3):

Saw a lactation consultant before leaving hospital ( $\mathrm{t} 3)$ :

Still breastfeeding at 4-months postpartum (t3):
Combination of the following: "Have you been pregnant before?"; "Have you ever experienced a miscarriage, stillbirth, abortion, neonatal death or live birth?"

"Have you ever experienced feeling sad, blue, depressed or down for most of the time for at least 2 weeks?"

Based on 5 questions: "Have you ever experienced physical abuse; emotional abuse; sexual abuse; financial abuse; or neglect?"

"How many weeks pregnant were you when your baby was born?"

"After your baby was born, how long was their hospital stay?"

"Has your baby stayed overnight in the hospital (not including when he/she was first born nor NICU)? How many times each?"

"Was your first attempt at breastfeeding your baby within $24 \mathrm{~h}$ of giving birth?"

"Were you able to successfully breastfeed on Yes/no your first attempt?"

"Were you able to breastfeed before you Yes/no went home from the hospital?"

"Did you see a lactation consultant before you went home from the hospital?"

"Are you still breastfeeding your baby?" Yes/no

Yes/no

Yes/no

Yes/No

Yes/no

Yes/no

Yes/no
10 item questionnaire. Each item rated on a 5-point Likert scale from 1 to 5 . After reverse scoring for some items, a total score is derived (range 10-50). Higher scores reflect better parenting morale. A cut-off at the 20th percentile of the sample distribution was used to classify women as reporting low parenting morale. Participants are instructed to respond to each item with respect to their daily life as a parent. Example items include: "optimistic"; "contented"; satisfied"

Number of weeks. We categorized gestational age at birth into two groups: late preterms $\left(34-36^{6 / 7}\right.$ weeks gestational age at birth) and terms $(38+$ weeks gestational age at birth)

Number of days

Selected/non selected; number of times. This variable was dichotomized into none versus at least once

${ }^{a} t 1<24$ weeks gestational age, $t 2$ 34-36 weeks gestational age, $t 34$-months postpartum

\section{References}

1. Doyle, L. W., \& Anderson, P. J. (2010). Adult outcome of extremely preterm infants. Pediatrics, 126(2), 342-351.

2. McCormick, M. C., Litt, J. S., Smith, V. C., \& Zupancic, J. A. F. (2011). Prematurity: An overview and public health implications. Annual Review of Public Health, 32, 367-379.

3. Saigal, S., \& Doyle, L. (2008). An overview of mortality and sequelae of preterm birth from infancy to adulthood. Lancet, 371(9608), 261-269.

4. Stephens, B., \& Vohr, B. (2009). Neurodevelopmental outcome of the premature infant. Pediatric Clinics of North America, 56(3), 631-646.
5. Engle, W. A., Tomashek, K. M., \& Wallman, C. (2007). The Committee on Fetus and Newborn. "Late-preterm" infants: A population at risk. Pediatrics, 120(6), 1390-1401.

6. Davidoff, M. J., Dias, T., Damus, K., et al. (1992). Changes in the gestational age distribution among U.S. singleton births: Impact on rates of late preterm birth, 1992 to 2002. Seminars in Perinatology, 30(1), 8-15.

7. Canadian Institute for Health Information. (2009). Too early, too small: A profile of small babies across Canada. Ottawa, ON: CIHI.

8. Howson, C. P., Merialdi, M., Lawn, J. E., Requejo, J. H., \& Say, L. (2009) March of dimes white paper on preterm birth: the global and regional toll. White Plains, NY: March of Dimes 
Foundation. Available online. URL: http://www.marchofdimes. com.

9. Martin, J. A., Hamilton, B. E., \& Sutton, P. D., et al. (2007). Births: Final data for 2005. National Vital Statistics Reports, 56(6), 1-103. Hyattsville, MD: National Center for Health Statistics.

10. Hamilton, B. E., Martin, J. A., \& Ventura, S. J. (2007). Births: Preliminary data for 2006. National Vital Statistics, 56, 1-18. Hyattsville, MD: National Center for Health Statistics.

11. Martin, J. A., Hamilton, B. E., \& Sutton, P. D., et al. (2010). Births: Final data for 2007. National Vital Statistics Reports, 58(24), 1-125. Hyattsville, MD: National Center for Health Statistics.

12. Clark, R. H. (2005). The epidemiology of respiratory failure in neonates born at an estimated gestational age of 34 weeks or more. Journal of Perinatology, 25, 251-257.

13. Wang, M. L., Dorer, D. J., Fleming, M. P., \& Catlin, E. A. (2004). Clinical outcomes of near-term infants. Pediatrics, 114(2), 372-376.

14. Cleaveland, K. (2010). Feeding challenges in the late preterm infant. Neonatal Network, 29(1), 37-41.

15. Lubow, J. M., How, H. Y., Habli, M., Maxwell, R., \& Sibai, B. M. (2009). Indications for delivery and short-term neonatal outcomes in late preterm as compared with term births. American Journal of Obstetrics and Gynecology, 200(5), e30-e33.

16. McIntire, D. D., \& Leveno, K. J. (2008). Neonatal mortality and morbidity rates in late preterm births compared with births at term. Obstetrics and Gynecology, 111(1), 35-41.

17. Raju, T. N., Higgins, R. D., Stark, A. R., \& Leveno, K. J. (2006). Optimizing care and outcome for late-preterm (near-term) infants: a summary of the workshop sponsored by the national institute of child health and human development. Pediatrics, 118(3), 1207-1214.

18. Shapiro-Mendoza, C. K., Tomashek, K. M., Kotelchuck, M., et al. (2008). Effect of late-preterm birth and maternal medical conditions on newborn morbidity risk. Pediatrics, 121(2), e223e232.

19. Escobar, G. J., Clark, R. H., \& Greene, J. D. (2006). Short-term outcomes of infants born at 35-36 weeks gestation: We need to ask more questions. Seminars in Perinatology, 30(1), 28-33.

20. Kramer, M. S., Demissie, K., Yang, H., Platt, R. W., Sauve, R., \& Liston, R. (2000). The contribution of mild and moderate preterm birth to infant mortality. JAMA, 284(7), 843-849.

21. Tomashek, K. M., Shapira-Mendoza, C. K., Weiss, J., et al. (2006). Early discharge among late preterm and term newborns and risk of neonatal morbidity. Seminars in Perinatology, 30(2), 61-68.

22. Shapiro-Mendoza, C. K., Tomashek, K. M., Kotelchuck, M., Barfield, W., Weiss, J., \& Evans, S. (2006). Risk factors for neonatal morbidity and mortality among "healthy" late preterm newborns. Seminars in Perinatology, 30(2), 54-60.

23. McGowan, J. E., Alderdice, F. A., Holmes, V. A., \& Johnston, L. (2011). Early childhood development of late-preterm infants: A systematic review. Pediatrics, 127(6), 1111-1124.

24. Jain, L. (2008). School outcome in late preterm infants: A cause for concern. Journal of Pediatrics, 153(1), 5-6.

25. Talge, N., Holzman, C., Wang, J., Lucia, V., Gardiner, J., \& Breslau, N. (2011). Late-preterm birth and its association with cognitive and socioemotional outcomes at 6 years of age. Obstetrical \& Gynecological Survey, 66(4), 193-195.

26. Morse, S. B., Zheng, H., Tang, Y., \& Roth, J. (2009). Early school-age outcomes of late preterm infants. Pediatrics, 123(4), e622-e629.

27. Chyi, L. J., Lee, H. C., Hintz, S. R., Gould, J. B., \& Sutcliffe, T. L. (2008). School outcomes of late preterm infants: special needs and challenges for infants born at 32-36 weeks gestation. Journal of Pediatrics, 153(1), 25-31.
28. Gurka, M. J., LoCasale-Crouch, J., \& Blackman, J. A. (2010). Long-term cognition, achievement, socioemotional, and behavioral development of healthy late-preterm infants. Archives of Pediatrics and Adolescent Medicine, 164(6), 525-532.

29. Voegtline, K. M., Stifter, C. A., \& The Family Life Project investigators. (2010). Late preterm birth, maternal symptomatology and infant negativity. Infant Behavior and Development, 33(4), 545-554.

30. Avan, B., Richter, L. M., Ramchandani, P. G., Norris, S. A., \& Stein, A. (2010). Maternal postnatal depression and children's growth and behaviour during the early years of life: Exploring the interaction between physical and mental health. Archives of Disease in Childhood, 95(9), 690-695.

31. Barker, E. D., Jaffee, S. R., Uher, R., \& Maughan, B. (2011). The contribution of prenatal and postnatal maternal anxiety and depression to child maladjustment. Depression and Anxiety, 28(8), 696-702.

32. Grace, S. L., Evindar, A., \& Stewart, D. E. (2003). The effect of postpartum depression on child cognitive development and behavior: a review and critical analysis of the literature. Archives of Women's Mental Health, 6(4), 263-274.

33. Murray, L., \& Cooper, P. (1997). Postpartum depression and child development. Psychological Medicine, 27(2), 253-260.

34. Murray, L., Fiori-Cowley, A., Hooper, R., \& Cooper, P. (1996). The impact of postnatal depression and associated adversity on early mother-infant interactions and later infant outcome. Child Development Perspectives, 67(5), 2512-2526.

35. Davis, L., Edwards, H., Mohay, H., \& Wollin, J. (2003). The impact of very premature birth on the psychological health of mothers. Early Human Development, 73(1-2), 61-70.

36. Karatzias, A., Chouliara, Z., Maxton, F., Freer, Y., \& Power, K. (2007). Post-traumatic symptomatology in parents with premature infants: A systematic review of the literature. Journal of Prenatal and Perinatal Psychology and Health, 21(3), 249-260.

37. Miles, M. S., Holditch-Davis, D., Burchinal, M., \& Nelson, D. (1999). Distress and growth in mothers of medically fragile infants. Nursing Research, 48(3), 129-140.

38. Miles, M. S., Holditch-Davis, D., Schwartz, T. A., \& Scher, M. (2007). Depressive symptoms in mothers of prematurely born infants. Journal of Developmental and Behavioral Pediatrics, 28(1), 36-44.

39. Zanardo, V., Freato, F., \& Zacchello, F. (2003). Maternal anxiety upon NICU discharge of high-risk infants. Journal of Reproductive and Infant Psychology, 21(1), 69-75.

40. Brandon, D. H., Tully, K. P., Silva, S. G., Malcolm, W. F., Murtha, B. S., \& Holditch-Davis, D. (2011). Emotional responses of mothers of late-preterm and term infants. Journal of Obstetric, Gynecologic, and Neonatal Nursing, 40(6), 719-731.

41. Zanardo, V., Gambina, I., Begley, C., et al. (2011). Psychological distress and early lactation performance in mothers of late preterm infants. Early Human Development, 87(4), 321-323.

42. Statistics Canada. (2008). Canadian Community Health Survey 2008 Questionnaire. Ottawa, ON: Ministry of Industry. Available online. URL: http://www.statcan.gc.ca/imdbbmdi/instrument/ 3226_Q1_V5-eng.pdf.

43. Golding, J. (2009). Data organization and preparation for statistical analysis in a longitudinal birth cohort. Paediatric and Perinatal Epidemiology, 23(Suppl. 1), 219-225.

44. Cox, J., Holden, J., \& Sagovsky, R. (1987). Detection of postnatal depression. Development of the 10-item edinburgh postnatal depression scale. British Journal of Psychiatry, 150, 782-786.

45. Cohen, S., Kamarck, T., \& Mermelstein, R. (1983). A global measure of perceived stress. Journal of Health and Social Behavior, 24(4), 385-396.

46. Spielberger, C., Gorsuch, R., \& Lushene, R. (1970). Test manual for the state-trait anxiety inventory. Palo Alto, CA: Consulting Psychologist's Press. 
47. Trute, B., \& Hiebert-Murphy, D. (2005). Predicting family adjustment and parenting stress in childhood disability services using brief assessment tools. Journal of Intellectual Developmental Disability, 30(4), 217-225.

48. Hosmer, D. W., \& Lemeshow, S. (1989). Applied logistic regression. Toronto, ON: Wiley.

49. Beck, C. T. (1996). A meta-analysis of predictors of postpartum depression. Nursing Research, 45(5), 297-303.

50. Beck, C. T. (2001). Predictors of postpartum depression: An update. Nursing Research, 50(5), 275-285.

51. O'Hara, M. W., \& Swain, A. M. (1996). Rates and risk of postpartum depression-a meta-analysis. International Review of Psychiatry, 8(1), 37-54.

52. Chalmers, B., Dzakpasu, S., Heaman, M., \& Kaczorowski, J. (2008). The maternity experiences survey: An overview of findings. Journal of Obstetrics and Gynaecology Canada, 30(3), 217-228.

53. Radtke, J. V. (2011). The paradox of breastfeeding-associated morbidity among late preterm infants. Journal of Obstetric, Gynecologic, and Neonatal Nursing, 40(1), 9-24.

54. Paul, I. M., Lehman, E. B., Hollenbeak, C. S., \& Jeffrey Maisels, M. (2006). Preventable newborn readmissions since passage of the newborns' and mothers' health protection act. Pediatrics, 118(6), $2349-2358$
55. Walker, M. (2008). Breastfeeding the late preterm infant. Journal of Obstetric, Gynecologic, and Neonatal Nursing, 37(6), 692-701.

56. Adamkin, D. H. (2006). Feeding problems in the late preterm infant. Clinics in Perinatology, 33(4), 831-837.

57. World Health Organization. (2003). UNICEF: Global strategy for infant and young child feeding. Geneva, Switzerland: World Health Organization.

58. Karatas, J. C., Matthey, S., \& Barnett, B. (2009). Antenatal psychosocial assessment: how accurate are we in determining 'low-risk' status? A pilot study. Archives of Womens Mental Health, 12(2), 97-103.

59. Matthey, S., Phillips, J., White, T., et al. (2004). Routine psychosocial assessment of women in the antenatal period: Frequency of risk factors and implications for clinical services. Archives of Womens Mental Health, 7(4), 223-229.

60. Austin, M. P., \& Lumley, J. (2003). Antenatal screening for postnatal depression: A systematic review. Acta Psychiatrica Scandinavica, 107(1), 10-17.

61. Boyle, E. M., Poulsen, G., Field, D. J., et al. (2012). Effects of gestational age at birth on health outcomes at 3 and 5 years of age: population based cohort study. BMJ, 344, 1-14. 